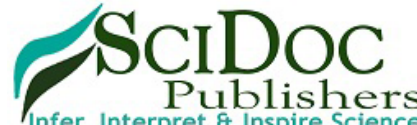

\author{
International Journal of Dentistry and Oral Science (IJDOS) \\ ISSN: 2377-8075
}

\title{
Green Synthesis of Copper oxide Nanoparticles Using Aqueous Extract of Ocimum sanctum and Analysis of Antimicrobial, Anti-inflammatory and Cytotoxic activity of Ocimum sanctum Copper Oxide Nanoparticles - An in vitro study \\ Research Article
}

Saravanan ${ }^{1}$, Jaiganesh Ramamurthy ${ }^{2 *}$, Nadathur Duraisamy Jayakumar ${ }^{3}$

${ }^{1}$ Department of Periodontics, Department of Periodontics, Saveetha dental college and Hospitals, Saveetha Institute of Medical and Technical Sciences (SIMATS), Saveetha University, Chennai, India.

${ }^{2}$ Professor and Head, Department of Periodontics, Saveetha dental college and Hospitals, Saveetha Institute of Medical and Technical Sciences (SIMATS), Saveetha University, Chennai, India.

${ }^{3}$ Professor, Department of Periodontics, Saveetha dental college and Hospitals, Saveetha Institute of Medical and Technical Sciences (SIMATS), Saveetha University, Chennai, India.

Abstract

Introduction: Nanotechnology is one of the major research which has been going towards greater advances for research purposes. Nowadays nanoparticles have been used in medical research as the size of nanoparticle 100nm enters in the blood vessels, tissues in a shorter period of time. This might give a faster healing process .Ocimum sanctum which is a plant extract has medicinal values and it has been used in Asian countries which has an antioxidant agent.

Materials and Methods: Ocimum sanctum powder extract is prepared and incorporated with copper oxide nanoparticles In which anti-inflammatory activity is done with diclofenac sodium with sample and standard preparation, antimicrobial activity was done in pathogenic strains of streptococcus mutans, streptococcus aureus, and lactobacillus strains and cytotoxic activity is tested with biologic organism of nauplii.

Results: The anti-inflammatory activity shows the that Cuo nanoparticles shows little significance differences with standard preparation, antimicrobial activity shows the greater zone of inhibition in lactobacillus strains compared with streptococcus mutans and streptococcus aureus and cytotoxic activity shows the mortality rate of Cuo nanoparticles with ocimum sanctum in which $10 \mu$ l.

Conclusion: The above results shows that ocimum sanctum with Cuo nanoparticles has shown that it has anti-inflammatory activity against the bacteria, antimicrobial activity has been seen in pathogenic strains to be known about and cytotoxic activity shows the mortality rate. The nanoparticles studies are being studied in the field of medicine due to action of particle size.

Keywords: Copper Oxide (Cuo); Ocimum Sanctum (Os); Nanoparticles (NPs); Periodontitis.

\section{Introduction}

Ocimum sanctum is commonly known as holy basil and is an aromatic plant family member of Lamiaceae. Ocimum sanctum (Tulsi) is a medicinal herb abundantly found and cultured in India, Malaysia, Australia, West Africa, and some of the Arab countries [1]. Ocimum sanctum has been used in tea and it also has a medicinal value and it has been used in treatment of bronchitis, asthma, malaria, diarrhoea, flu in India.
Ocimum sanctum also contains Vitamin $\mathrm{C}$ and antioxidant activity. It also has antibacterial agents namely carvacrol and terpene. Tulsi tastes hot and bitter and is claimed to penetrate the deep tissues, dry tissue secretions and normalize kapha and vata. Daily consumption of tulsi is claimed to stop disease, promote general health, well being and longevity and assist in handling the stresses of lifestyle. Tulsi is additionally credited with giving luster to the complexion, sweetness to the voice and fostering beauty, intelligence, stamina and a relaxed emotional. In addition to those

*Corresponding Author:

Jaiganesh Ramamurthy,

Professor and Head, Department of Periodontics, Saveetha dental college and Hospitals, Saveetha Institute of Medical and Technical Sciences (SIMATS), Saveetha University, 162, PH Road, Chennai 600077, India.

Tel: +91 - 9840443463

E-mail: jaiganeshr@saveetha.com

Received: April 28, 2021

Accepted: June 22, 2021

Published: June 30, 2021

Citation: Saravanan, Jaiganesh Ramamurthy, Nadathur Duraisamy Jayakumar. Green Synthesis of Copper oxide Nanoparticles Using Aqueous Extract of Ocimum sanctum and Analysis of Antimicrobial, Anti-inflammatory and Cytotoxic activity of Ocimum sanctum Copper oxide nanoparticles-An in vitro study. Int J Dentistry Oral Sci. $2021 ; 8(6): 2848-2852$. doi: http://dx.doi.org/10.19070/2377-8075-21000578

Copyright: Jaiganesh Ramamurthy 2021 . This is an open-access article distributed under the terms of the Creative Commons Attribution License, which permits unrestricted use, distribution and reproduction in any medium, provided the original author and source are credited. 
health-promoting properties, tulsi is recommended as a treatment for a range of conditions including anxiety, cough, asthma, diarrhoea, fever, dysentery, arthritis, eye diseases, otalgia, indigestion, hiccups, vomiting, gastric, cardiac and genitourinary disorders, back pain, scorpion bites and malaria.

Nanomaterials are synthesized by sol process, micelle, chemical precipitation, hydrothermal method, pyrolysis, or chemical vapour deposition [2]. Synthesis of nanoparticles makes them more biocompatible and environmentally benign. Copper oxide is a compound formed of two elements copper and oxygen. It is also a skin disease, ringworm, insect, snake found in all body tissues and plays a role in making red blood cells, maintaining nerve cells and the immune system [3]. It also helps body from collagen and absorbs iron and plays a role in energy production .Most of the copper in the body is found in the liver, brain, heart, kidney, and skeletal muscles. Nanoparticles have advantages in medicine; it can't only circulate widely throughout the body but also enter cells or be designed to bind to specific cells. Those properties have enabled new ways of enhancing images of organs as well as tumours and other diseased tissues in the body. They even have facilitated the event of latest methods of delivering therapy, like by providing local heating (hyperthermia), by blocking vasculature to diseased tissues and tumours, or by carrying payloads of drugs.

Periodontitis occurs as the inflammation reaches the periodontal ligament and alveolar bone which leads to tooth loss [4]. Periodontal pathogens generate deteriorating by-products and enzymes that dissolves the extracellular matrices as well as host cell membranes to generate nutrients for their growth and function [5]. Chlorhexidine (CHX), a cationic bisbiguanide is a gold standard among all mouthwashes particularly because of its substantivity and broad-spectrum antibacterial activity $[6,7]$. However, $\mathrm{CHX}$ has been reported to have a number of side effects like brown discoloration of teeth, salt taste perturbation, oral mucosal erosions, and enhanced supragingival calculus formation, which limit its long-term use $[8,9]$.

Many current researches are done based on leaf extract as a mouthwash and the introduction of nanoparticles which might give better results than commercial uses of mouthwash. Aqueous extract of plant extract may useful for reduction of plaque and calculus The current research on Cuo nanoparticles using aqueous extract which has been done to analysis the anti-inflammatory, antimicrobial and cytotoxic activity can be used as mouthwash in periodontal therapy. Hence aim of the current study was to develop Green Synthesis of Copper oxide Nanoparticles Using Aqueous Extract of Ocimumsanctum.Previously we worked on plenty of topic in periodontics [10-20].

\section{Materials And Methods}

\section{Preparation of leaf extract}

Aqueous extract is prepared by following procedure. Ocimum sanctum powder is prepared. Then the extract powered is weighted in a weighing machine $0.2 \mathrm{~g}$ of ocimum sanctum and $50 \mathrm{ml}$ of distilled water is added to prepare the aqueous extract.

\section{Preparation of ocimum sanctum with Cuo nanoparticles}

The aqueous extract of ocimum sanctum prepared extract is mixed with Cuo nanoparticles and kept in the magnetic stirrer for 24 hours in which the nanoparticles gets incorporated with ocimum sanctum.

\section{Evaluation of Ant-inflammatory activity}

BSA (Bovine serum albumin) was used as reagent assay to make up $60 \%$ of all proteins in animal serum. BSA undergoes denaturation upon heating and starts expressing antigens associated with Type III hypersensitivity reaction which is related to diseases such as rheumatoid arthritis, glomerulonephritis, serum sickness, and systemic lupus erythematosus. Two sample preparations are prepared in anti-inflammatory activity. Sample preparation in which $2 \mathrm{ml}$ of $1 \%$ bovine serum albumin is added in all test tubes and the prepared solution is added in a range of $10 \mu \mathrm{l}, 20 \mu \mathrm{l}, 30 \mu \mathrm{l}, 40 \mu \mathrm{l}$, $50 \mu \mathrm{l}$ in all test tubes Standard preparation: Diclofenac sodium is added in $2 \mathrm{ml}$ of $1 \%$ bovine serum albumin is added instead of prepared solution in a range of $10 \mu \mathrm{l}, 20 \mu \mathrm{l}, 30 \mu \mathrm{l}, 40 \mu \mathrm{l}, 50 \mu \mathrm{l}$ in all test tubes see.

\section{Evaluation of Antimicrobial activity}

Kirby-Bauer disk diffusion is a test which uses antibiotic impregnated paper disk test to determine whether particulate bacteria are susceptible to mouthwash. A known quantity of bacteria are grown in agar plates in the presence of thin filter paper discs containing relevant bacterial strains. If susceptible bacteria an area of clearing surrounds the wafer called zone of inhibition. Zone of inhibition testing is fast and inexpensive relative to other laboratory tests for antimicrobial activity. Zone of inhibition testing is especially well suited for determining (albeit qualitatively) the ability of water-soluble antimicrobials to inhibit the growth of microorganisms. A number of samples can be screened for antimicrobial properties quickly using this test method. A variety of antimicrobial product types can be tested using this method. Liquids, coated antimicrobial surfaces, and antimicrobial-impregnated solid products can all be tested for their ability to produce a zone of inhibition. Samples of Cuo with Ocimum sanctum are tested with the strains of Streptococcus mutans, Streptococcus aureus, and Lactobacillus. The antimicrobial activities of the extract were determined by agar diffusion assay. The Petri Dish was incubated for 24 hours at 37 Celsius in bacterial strains. The diameter of the zone of Inhibition is indicated clearly which was devoid of growth of microbes.

\section{Evaluation of Cytotoxic activity}

Cytotoxic Assessment was done by brine shrimp egg. In which brine shrimp eggs are kept in the fish tank and iodide free salt is added in the beaker along with water then stirred for 10 minutes till the crystallized salt gets dissolved then added in the fish tank with a pinch of sodium bicarbonate. The brine shrimp eggs were kept in the tank for 24 hours. After 24 hours nauplii were hatched then 10 napili is added in each Elisa well and Cuo nanoparticles with ocimum sanctum is added in the range of $10 \mu \mathrm{l}, 20 \mu \mathrm{l}, 30 \mu \mathrm{l}$, $40 \mu \mathrm{l}, 50 \mu \mathrm{l}$ in all wells and control level also added. To determine the mortality rate of prepared synthesis of Cuo nanoparticles 
along with ocimum sanctum.

\section{Results and Discussion}

An in vitro study was done based on Cuo NP using aqueous extract of ocimum sanctum to detect the anti-inflammatory, antimicrobial, and cytotoxic activity ocimum sanctum. In which antiinflammatory activity of Ocimum sanctum were assessed in two preparation done $\mathrm{Cu}$ Nps preparation (76.7) and standard preparation shows (86.5)(Figure 1)(Table 1)

Antimicrobial activity was done in streptococcus mutant's shows absorbent of 30, Streptococcus aureus shows absorbent of 18 and Lactobacillus shows absorbent 43 which each bacteria results was determined in $50 \mu \mathrm{l}, 100 \mu \mathrm{l}$ and $150 \mu \mathrm{l}$ (Figure 2)(Table2).

Cytotoxic activity was done in napili which in each concentration nanoparticles are added in different concentration to identify the mortality rate which $10 \mu \mathrm{l}$ shows $30 \%$ of mortality rate, $20 \mu \mathrm{l}$ show $20 \%, 30 \mu \mathrm{l}$ shows $10 \%, 40 \mu \mathrm{l}$ shows $20 \%$ and $50 \mu \mathrm{l}$ shows $10 \%$ (Figure 3)(Table3).

The preparations were measured in a single beam UV spectrophotometer. The preparations were measured in a single beam UV spectrophotometer and the absorbance value was recorded at $660 \mathrm{~nm}$. Both samples were measured and calculated.
They are measured \% Inhibition = Control O.D-sample O.D/ Control OD $* 100$. The table content results shows that Cuo nanoparticles with ocimum sanctum and standard value have little differences in the anti-inflammatory activity. Yellow colour shows $\mathrm{Cu}$ Nps preparation and Green colour denotes standard preparation.

The study was conducted to know that Ocimum sanctum with Cuo nanoparticle as mouthwash would be given as an alternative adjunct therapy for chronic periodontitis. As ocimum sanctum which has antioxidant activity it can act as a defense mechanism in periodontal therapy with the nanoparticles alongside ocimum sanctum. The nanoparticles are ultrafine particles, and therefore, the structural dimension is $100 \mathrm{~nm}$. It also penetrates and gives faster healing compared to other nanoparticles. Even Though chlorhexidine mouthwash is standard, with prolonged usage, it also shows side effects after. The usage of ocimum sanctum with Cuo nanoparticles might exhibit no side effects because the herbal products don't show any side effects for prolonged usage. But the Ocimum sanctum roots are used to evaluate the ethyl acetate fraction (STE) that exhibits the most potent anti-inflammatory activity [21]. Dose response study of STE showed anti-inflammatory, analgesic and antipyretic potential in dose-dependent manner without any toxic effect at dose $2000 \mathrm{mg} / \mathrm{kg}$.Silver nanoparticle was studied in ocimumtenuiflorum in which the antimicrobial activity was studies under strains of Staphylococcus aureus Pseudomonas aeruginosa, Klebsiellapneumoniae and Escherichia coli. The highest antimicrobial activity of silver nanoparticles synthesized by

Figure 1. Shows the anti-inflammatory activity which two preparations were prepared standard and Cu NPs preparation which preparation were heated for 1 hour and to detect anti-inflammatory activity by Uv-spectrometer with a wavelength range 660 .
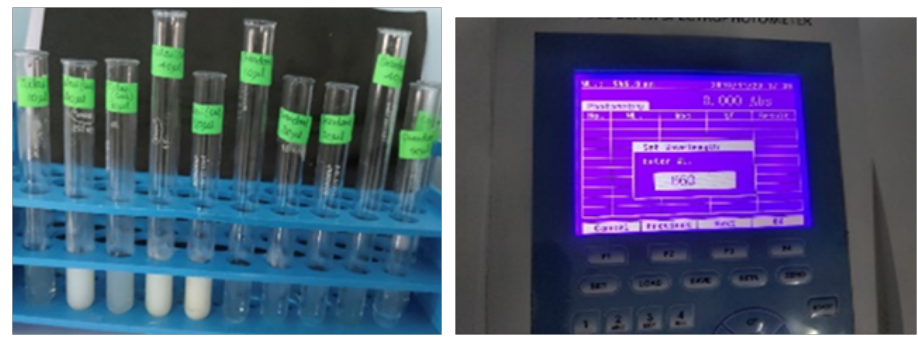

Table 1. The preparations were measured in a single beam UV spectrophotometer. The preparations were measured in a single beam UV spectrophotometer and the absorbance value was recorded at $660 \mathrm{~nm}$. Both samples were measured and calculated.

\begin{tabular}{|c|c|c|c|c|c|}
\hline & WAVELENGTH & ABSORBENTS & & Cu NPs & STANDARD \\
\hline $10 \mu \mathrm{l}$ & 660 & 0.811 & $10 \mu \mathrm{l}$ & 18.9 & 79.2 \\
\hline $20 \mu \mathrm{l}$ & 660 & 0.736 & $20 \mu \mathrm{l}$ & 26.4 & 83.9 \\
\hline $30 \mu \mathrm{l}$ & 660 & 0.422 & $30 \mu \mathrm{l}$ & 57.8 & 84.4 \\
\hline $\mathrm{w} 40 \mu \mathrm{l}$ & 660 & 0.308 & $40 \mu \mathrm{l}$ & 69.2 & 84.5 \\
\hline $50 \mu \mathrm{l}$ & 660 & 0.233 & $50 \mu \mathrm{l}$ & 76.7 & 86.5 \\
\hline & STANDARD & & & & \\
\hline $10 \mu \mathrm{l}$ & 660 & 0.208 & & 79.2 & \\
\hline $20 \mu \mathrm{l}$ & 660 & 0.161 & & 83.9 & \\
\hline $30 \mu \mathrm{l}$ & 660 & 0.156 & & 84.4 & \\
\hline $40 \mu \mathrm{l}$ & 660 & 0.155 & & 84.5 & \\
\hline $50 \mu \mathrm{l}$ & 660 & 0.135 & & 86.5 & \\
\hline
\end{tabular}

They are measured \% Inhibition $=$ Control O.D-sample O.D / Control OD *100.The table content results shows that Cuo nanoparticles with ocimum sanctum and standard value have little differences in the anti-inflammatory activity. 
Figure 2. Shows the zones of inhibition for the microbes Streptococcus mutans, Streptococcus aureus and Lactobacillus for the prepared extract.
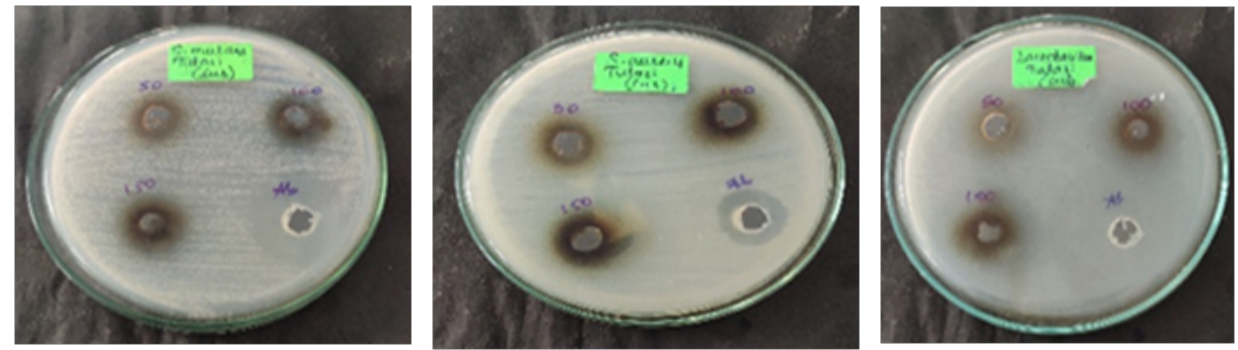

Table 2. Shows antimicrobial activity tests done at different concentrations $50 \mu 1,100 \mu 1$ and $150 \mu 1$ of which bacteria grows.

The bacterial growth was counted in each concentration and antibiotic of each bacteria is observed.

\begin{tabular}{|c|c|c|c|c|}
\hline MICROBE & $\mathbf{5 0} \boldsymbol{\mu 1}$ & $\mathbf{1 0 0} \boldsymbol{\mu}$ & $\mathbf{1 5 0} \boldsymbol{\mu l}$ & Antibiotic(Amoxicillin) \\
\hline STREPTOCOCCUS MUTANS & 12 & 17 & 20 & 30 \\
\hline STREPTOCOCCUS AUREUS & 12 & 15 & 20 & 18 \\
\hline LACTOBACILLUS & 30 & 35 & 40 & 43 \\
\hline
\end{tabular}

Table 3. Shows the mortality rate of CuoNps in each concentration. In which brine shrimp eggs were added along with iodide free salt water and in after 24 hours brine shrimps eggs hatched and nauplii were seen after 24 hours then the prepared CuoNps were added in each concentration of $10 \mu 1,20 \mu 1,30 \mu 1,40 \mu 1,50 \mu 1$.

\begin{tabular}{|c|c|c|}
\hline \multicolumn{3}{|c|}{ Ocimum sanctum with Cuo nanoparticle } \\
\hline CYTOTOXICITY & NAUPLII & NAUPLII \\
\hline & DAY 0 ALIVE & DAY 1 ALIVE \\
\hline $10 \mu \mathrm{l}$ & $100 \%$ & $30 \%$ \\
\hline $20 \mu \mathrm{l}$ & $100 \%$ & $20 \%$ \\
\hline $30 \mu \mathrm{l}$ & $100 \%$ & $10 \%$ \\
\hline $40 \mu \mathrm{l}$ & $100 \%$ & $20 \%$ \\
\hline $50 \mu \mathrm{l}$ & $100 \%$ & $10 \%$ \\
\hline
\end{tabular}

Figure 3. Shows that prepared CuoNps is added in different concentration $10 \mu 1,20 \mu 1,30 \mu 1,40 \mu 1,50 \mu 1$ and shows napili after 24 hours.

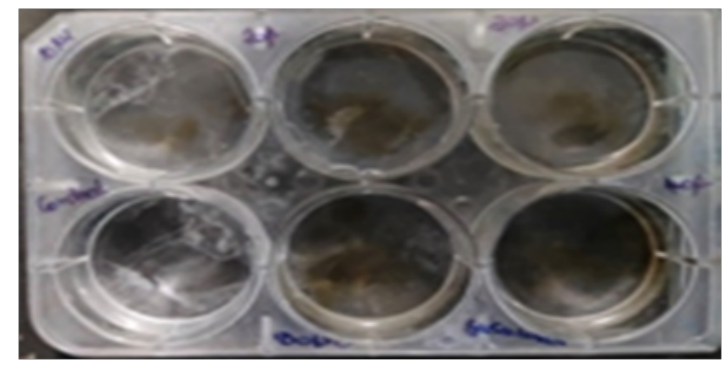

O. tenuiflorum extracts was found against $\mathrm{S}$. aureus $(30 \mathrm{~mm})$ and E. coli $(30 \mathrm{~mm})$ respectively [22]. AgNPs obtained showed significantly higher antimicrobial activities against Escherichia coli $(E$. coli) and Bacillus sp. in comparison to both $\mathrm{AgNO}_{3}$ and raw plant extracts [23]. The study was conducted by different herbal plants in which studies was done in biofilm and plaque and the results states that herbal extracts can be used to treat plaque-induced gingivitis in the form of mouthwash and toothpaste [24]. The study was conducted to study the Phytochemical and antimicrobial activity in which phytochemical activity is higher in ocimum sanctum compared to other plants [25].

The holy basil mouthwash has an antiplaque effect and is efficacious against P. intermedia and F. nucleatum strains in vitro [26]. Gingivitis is an chronic inflammatory disease which leads to periodontitis studies has been done based on herbs such as Neem,Guava,Pomegranate,Tulasi which herbal extracts are more effective than inorganic compound [27]. TulasiN nanoparticles has been studied under gold and silver nanoparticles which are tulsi extract of gold used to reduce silver nanoparticles [28]. Herbal mouthwash is used to compare with chlorhexidine mouthwash which herbal mouthwash found to potent bacterial growth compared with chlorhexidine mouthwash and herbal mouthwash can be used as alternative for patients with diabetic, Xerostomia [29]. Meta-analysis study was done by oral herbal product reducing gingivitis which suggests reducing plaque and calculus [30]. Nanoparticles are cost effective which kills bacterial endospores and it has effective pathogens and control microorganism. [31] Herbs such as Neem, Tulsi, Pomegranate, Guava, Caneberries are used to reduce plaque and gingivitis which organic compound are 
used to reduce gingivitis and has no side effects compared to inorganic compound [30]. Ocimum sanctum has antimicrobial ,anti stress and antihyperlipidemic activity which is used to treat gingivitis and periodontitis.

\section{Conclusion}

Within the limits of the study we were able to successfully synthesise copper oxide nanoparticles and infuse it with ocimum sanctum and analysed the anti-inflammatory activity, antimicrobial properties and cytotoxic activity. We have found that the synthesised product has anti-inflammatory and antimicrobial properties and also we have found that the synthesised product is non-toxic in nature through cytotoxic tests.

Further studies have to be done before using this novel product as mouthwash in patients with periodontal diseases.

\section{Acknowledgement}

The authors are thankful to the Director of academics, Chancellor and Dean of Saveetha Dental College and Hospitals for providing us a platform to do research activities.

\section{References}

[1]. Mondal S, Mirdha BR, Mahapatra SC. The science behind sacredness of Tulsi (Ocimum sanctum Linn.). Indian J Physiol Pharmacol. 2009 OctDec;53(4):291-306. Pubmed PMID: 20509321.

[2]. N V, Vasanth N, Melchias G, et al. Biogenic silver nanoparticles mediated by Broussonetiapapyrifera: anticancer and antimicrobial activity against pathogenic organisms. Asian Journal of Pharmaceutical and Clinical Research 2017; 10: 93.

[3]. Vishnuvarthanan M, Rajeswari N. Plant mediated greener approach for synthesis of silver nanoparticles from Digitalis purpurea plant and its antibacterial activity. International Journal of Nanoparticles. 2017;9(3):166-79.

[4]. Lindhe J, Lang NP, Karring T. Clinical Periodontology and Implant Dentistry, 2 Volumes. Wiley-Blackwell, 2008.

[5]. Vyas SP, Sihorkar V, Mishra V. Controlled and targeted drug delivery strategies towards intraperiodontal pocket diseases. J Clin Pharm Ther. 2000 Feb;25(1):21-42. Pubmed PMID: 10771461.

[6]. Van Leeuwen MP, Slot DE, Van der Weijden GA. Essential oils compared to chlorhexidine with respect to plaque and parameters of gingival inflammation: a systematic review. J Periodontol. 2011 Feb;82(2):174-94. Pubmed PMID: 21043801.

[7]. Rolla G, Loe H, Schiott CR. Retention of chlorhexidine in the human oral cavity. Arch Oral Biol. 1971 Sep;16(9):1109-16. Pubmed PMID: 5293410.

[8]. Flötra L, Gjermo P, Rölla G, Waerhaug J. Side effects of chlorhexidine mouth washes. Scand J Dent Res. 1971;79(2):119-25. Pubmed PMID: 5280246.

[9]. Overholser CD Jr. Longitudinal clinical studies with antimicrobial mouthrinses. J Clin Periodontol. 1988 Sep;15(8):517-9. Pubmed PMID: 3053794.

[10]. Ramamurthy J, Jayakumar ND. Ocimum sanctum and its effect on oral health-A comprehensive review. Drug Invention Today. 2019 Apr 1;11(4).

[11]. Arjunkumar R. Nanomaterials for the management of periodontal diseases. InDental Applications of Nanotechnology 2018 (pp. 203-215). Springer, Cham.

[12]. Ravi S, Malaiappan S, Varghese S, Jayakumar ND, Prakasam G. Additive Effect of Plasma Rich in Growth Factors With Guided Tissue Regeneration in Treatment of Intrabony Defects in Patients With Chronic Periodontitis: A Split-Mouth Randomized Controlled Clinical Trial. J Periodontol. 2017 Sep;88(9):839-845. Pubmed PMID: 28474968.

[13]. Murthykumar K, Arjunkumar R, Jayaseelan VP. Association of vitamin D receptor gene polymorphism (rs10735810) and chronic periodontitis. J Investig Clin Dent. 2019 Nov;10(4):e12440. Pubmed PMID: 31325246.

[14]. Ramesh A, Vellayappan R, Ravi S, Gurumoorthy K. Esthetic lip repositioning: A cosmetic approach for correction of gummy smile - A case series. J Indian Soc Periodontol. 2019 May-Jun;23(3):290-294. Pubmed PMID: 31143013.

[15]. Ramesh A, Varghese S, Jayakumar ND, Malaiappan S. Comparative estimation of sulfiredoxin levels between chronic periodontitis and healthy patients - A case-control study. J Periodontol. 2018 Oct;89(10):1241-1248. Pubmed PMID: 30044495

[16]. RAJESHWARAN N, RAMAMURTHY J, RAJESHKUMAR S. GREEN SYNTHESIS OF GRAPE SEED OIL MEDIATED SILVER NANOPARTICLE AND PREPARATION OF GEL-FOR PERIODONTAL DISEASES. PLANT CELL BIOTECHNOLOGY AND MOLECULAR BIOLOGY. 2020 Aug 26:32-42.

[17]. Ramesh A, Ravi S, Kaarthikeyan G. Comprehensive rehabilitation using dental implants in generalized aggressive periodontitis. J Indian Soc Periodontol. 2017 Mar-Apr;21(2):160-163. Pubmed PMID: 29398863.

[18]. ain M, Nazar N. Comparative Evaluation of the Efficacy of Intraligamentary and Supraperiosteal Injections in the Extraction of Maxillary Teeth: A Randomized Controlled Clinical Trial. J Contemp Dent Pract. 2018 Sep 1;19(9):1117-1121. Pubmed PMID: 30287714.

[19]. Vijayashree Priyadharsini J. In silico validation of the non-antibiotic drugs acetaminophen and ibuprofen as antibacterial agents against red complex pathogens. J Periodontol. 2019 Dec;90(12):1441-1448. Pubmed PMID: 31257588.

[20]. Ramamurthy JA, Mg V. Comparison of effect of hiora mouthwash versus chlorhexidine mouthwash in gingivitis patients: a clinical trial. Asian Journal of Pharmaceutical and Clinical Research. 2018;11(7):84-.

[21]. Priyadarshini HS, Kumar SA, Sakshi G, Rahul N. Phytochemical screening and antioxidant activity of methanolic extract of Ocimum sanctum Linn. Leaves. GSC Biological and Pharmaceutical Sciences. 2019;8(2).

[22]. Logeswari P, Silambarasan S, Abraham J. Synthesis of silver nanoparticles using plants extract and analysis of their antimicrobial property. Journal of Saudi Chemical Society. 2015 May 1;19(3):311-7.

[23]. Banerjee P, Satapathy M, Mukhopahayay A, Das P. Leaf extract mediated green synthesis of silver nanoparticles from widely available Indian plants: synthesis, characterization, antimicrobial property and toxicity analysis. Bioresources and Bioprocessing. 2014 Dec;1(1):1-0.

[24]. Southern EN, McCombs GB, Tolle SL, Marinak K. The comparative effects of $0.12 \%$ chlorhexidine and herbal oral rinse on dental plaque-induced gingivitis. J Dent Hyg. 2006 Winter;80(1):12. Pubmed PMID: 16451766.

[25]. Verma OP, Poonam S, Kamin A. Phytochemical Screening of Ocimum sanctum (Tulsi), Azadirachta indica (Neem) and Phyllanthus emblica (Amla). Int. J. Curr. Microbiol. Appl. Sci. 2019;8:682-6.

[26]. Hosamane M, Acharya AB, Vij C, Trivedi D, Setty SB, Thakur SL. Evaluation of holy basil mouthwash as an adjunctive plaque control agent in a four day plaque regrowth model. J Clin Exp Dent. 2014 Dec 1;6(5):e491-6. Pubmed PMID: 25674314.

[27]. Comparison of Clinical Efficacy of Two Herbal Dentifrices in Control of Plaque induced Gingivitis: A double Blind Clinical Trial. Indian Journal of Dental Education 2017; 10: 5-11.

[28]. Philip D, Unni C. Extracellular biosynthesis of gold and silver nanoparticles using Krishna tulsi (Ocimum sanctum) leaf. Physica E: Low-dimensional Systems and Nanostructures. 2011 May 1;43(7):1318-22.

[29]. Malhotra R, Grover V, Kapoor A, Saxena D. Comparison of the effectiveness of a commercially available herbal mouthrinse with chlorhexidine gluconate at the clinical and patient level. J Indian Soc Periodontol. 2011 Oct;15(4):349-52. Pubmed PMID: 22368358.

[30]. Janakiram C, Venkitachalam R, Fontelo P, Iafolla TJ, Dye BA. Effectiveness of herbal oral care products in reducing dental plaque $\&$ gingivitis - a systematic review and meta-analysis. BMC Complement Med Ther. 2020 Feb 11;20(1):43. Pubmed PMID: 32046707.

[31]. Brahmachari G, Sarkar S, Ghosh R, Barman S, Mandal NC, Jash SK, et al. Sunlight-induced rapid and efficient biogenic synthesis of silver nanoparticles using aqueous leaf extract of Ocimum sanctum Linn. with enhanced antibacterial activity. Org Med Chem Lett. 2014 Dec 29;4(1):18. Pubmed PMID: 25621198

[32]. Jaiganesh Ramamurthy, Jayakumar ND. Anti-inflammatory, anti-oxidant effect and cytotoxicity of Ocimum sanctum intra oral gel for combating periodontal diseases.Bioinformation2020;16(12): 1026-32. 